\title{
Archival sources on asbestos and silicosis in Southern Africa and Australia
}

\author{
Jock McCulloch ${ }^{1}$
}

(C) Macmillan Publishers Ltd., part of Springer Nature 2018

Mining has been the foundation of most Southern African economies. The industry's social impact has also been profound: it connected the region through a system of oscillating migration, with men working for periods at different gold or asbestos mines. During the twentieth century, South Africa produced most of the world's gold and virtually all of its crocidolite (blue) and amosite (brown asbestos). It was in South Africa that researchers discovered the connection between asbestos and mesothelioma [1]. The region has also produced chrysotile (white asbestos) from mines in Swaziland, Botswana, and Zimbabwe. The Zimbabwe mine at Shabanie is expected to re-open in the near future.

There are special challenges in researching the history of asbestos mining, gold mining, and occupational disease in Southern Africa. With the exception of Botswana, the regional archives lack funding and skilled staff, and the indexing is often idiosyncratic. Without patience and time, it is easy to miss important material. During minority rule, South Africa's archives were politicized. The gold mining industry, in particular, dictated which materials were saved and which discarded. Below I discuss the archives that have hitherto been difficult to access, but now all those who want to see documents from the collections will be aided by their presence in ToxicDocs [2].

\section{South Africa}

Because of the recent constitution (1994), the South African National Archives has a 'closed period' of just 10 years; researchers and the public have no access to materials that are $<10$ years old. In theory, this is among the most generous

Jock McCulloch

jock.mcculloch@rmit.edu.au

1 School of Global, Urban and Social Studies, RMIT University, Melbourne, Australia 
provisions in the world. In practice, the picture is very different. Because of a lack of staff and funding, there is a backlog of more than 60 years.

The National Archives' existing holdings are rich but poorly catalogued, especially with regard to occupational disease, medical knowledge, and state regulation. All of the best materials are now included in the ToxicDocs collection. The other public source is the TEBA (gold mining) Archive held at Johannesburg University. While extensive in terms of the number of items held, the materials have been selected and there are a limited number of documents on medical discovery, occupational disease, and compensation. As with the materials from the National Archives, all the most important documents have been copied to ToxicDocs.

\section{The Cape PLC papers}

In 2003, the British asbestos company, Cape PLC, settled out of court in London with former miners suffering from asbestos disease. The papers released during that case, including internal company correspondence, are available on ToxicDocs. The material, in English and Afrikaans, is of variable quality and ranges from low level correspondence on production levels to important state inspections and medical reviews. The material provides a unique insight into the daily operations of an asbestos company.

\section{The NIOH papers}

The National Institute for Occupational Health (NIOH) in Johannesburg is the most important research centre on miners' health. The Institute has undergone a number of name changes over its seventy-year history. The Institute was home to J.C. Wagner when he did his initial research on asbestos and mesothelioma. The NIOH Papers come from the now defunct library and cover the period from 1955 until the mid-1980s. They include suppressed surveys of asbestos exposure and health in the Northern Cape from the early 1960s, correspondence, reports, and unpublished data. The collection is small but extremely rich. It provides insight into a major research institute under minority rule.

\section{Interviews}

The collection includes interviews with key medical researchers such as Drs. J. C. Wagner, Paul Marchand, Ian Webester (the Director of the NIOH during the apartheid period), and his successor Prof J. C. A. Davies. 


\section{Theses}

Copies of a thesis by G. W. H. Slade (the first thesis on asbestosis among miners), J. C. Wagner's work on mesothelioma, Marianne Felix's work on asbestos disease and environmental exposure, and Anna Trapido's study of gold miners in the Eastern Cape can be found. The theses by Slade and Wagner are not available from any other source.

\section{Regional collections}

The Zimbabwe National Archives was one of the best facilities of its kind in the region. That is no longer the case. Over the past 15 years, the facility has decayed. Today, getting a research permit to use the archive may take a year and more. The ToxicDocs collection includes all of the archives' notable materials on asbestosis and silicosis, including key reports from the 1930s.

Zambia, Botswana, Swaziland, and Malawi all sent workers to South Africa's gold mines. Many of those miners returned home with occupational lung disease. The key documents from those national archives are included in ToxicDocs.

\section{Australia}

Australia has a federal system with the main holdings on asbestos mining being held at the Battye Library at the University of Western Australia. The holdings are incomplete, but contain valuable material on Wittenoom (1944-1966), the only crocidolite mine outside of South Africa. The gaps in the Battye Collection are offset by the Motley Rice Papers on Wittenoom gathered during litigation. That material includes copious internal correspondence from Australia Blue Asbestos Pty. Ltd.

\section{The Burke papers}

James Hardie Pty Ltd. dominated asbestos manufacture in Australia. Hardie also operated a chrysotile mine at Baryulgil in Northern NSW. The mine was staffed by an Aboriginal workforce that worked in conditions akin to apartheid in South Africa. The Burke Papers were collected secretly by the mine manager over a tenyear period and give a rare insight into the daily operations of an asbestos mine.

\section{References}

1. Wagner JC, Sleggs CA, Marchand Paul. Diffuse pleural mesothelioma and asbestos exposure in the North Western Cape Province. Br J Ind Med. 1960;17:260-71. 
2. Rosner D, Markowitz G, Chowkwanyun M. Guest Editorial: ToxicDocs (www.ToxicDocs.org): From history buried in stacks of paper to open, searchable archives online. J Public Health Policy [special section] "ToxicDocs: Opening a new era of evidence for policies to protect public health" (Guest Eds. Rosner D, Markowitz G, Chowkwanyun M). 2018;39(1). https://doi.org/10.1057/s41271-017-0106-8.

Jock McCulloch is a leading scholar of the global impact of the asbestos industry, having written such classics as, Asbestos Blues: labour, capital, physicians and the state in South Africa, (2002); Defending the indefensible: the global asbestos industry and its fight for survival, with Geoffrey Tweedale (2008); and South Africa's gold mines and the politics of silicosis, (2012). Most recently, he has been involved with lawsuits seeking redress from some of the world's largest and most powerful mining companies for imperilling the health of former gold miners in southern Africa. 